\title{
Mass modelling of pepper berries (Piper nigrum L.) with some physical properties
}

\author{
${ }^{1}$ Azman, P.N.M.A., ${ }^{1,2, *}$ Shamsudin, R., ${ }^{3}$ Che Man, H. and ${ }^{1}$ Ya'acob, M.E. \\ ${ }^{1}$ Department of Process and Food Engineering, Engineering Faculty, Universiti Putra Malaysia, 43400 \\ Serdang, Selangor, Malaysia. \\ ${ }^{2}$ Institute of Advanced Technology, Universiti Putra Malaysia, 43400 UPM, Serdang, Selangor, Malaysia. \\ ${ }^{3}$ Department of Biological and Agricultural Engineering, Engineering Faculty, Universiti Putra Malaysia, \\ 43400 Serdang, Malaysia
}

\begin{abstract}
Article history:
Received: 17 May 2020

Received in revised form: 15 August 2020

Accepted: 16 December 2020

Available Online: 3 January 2021
\end{abstract}

Keywords:

Pepper,

Mass modelling,

Physical properties,

Prediction

DOI:

https://doi.org/10.26656/fr.2017.5(S1).047

\begin{abstract}
The determination of correlations between mass with its physical properties such as dimensions, volume and projected area is crucial in the design and development of some post-harvest processing. In this study, the physical properties were measured, and the mass of Kuching pepper berries variety was predicted in four models including Linear, Quadratic, S-curve and Power. Thus, the study was aimed to determine the most applicable model for predicting pepper berry mass with their physical properties and determine some physical properties of pepper berries to form essential and useful information. The results showed that mass modelling based on the actual volume of pepper berries was more applicable compared to other properties with the highest determination coefficient, 0.995 at $1 \%$ probability level. From the economic standpoint, predicting mass based on actual volume as Quadratic form: $M=0.828-0.015 \mathrm{X}+7.376 \mathrm{x}$ $10^{-5} \mathrm{X}^{2}$ is recommended. This study can be applied for improvement in handling and packaging system in future.
\end{abstract}

\section{Introduction}

Generally, the botanical name of pepper is Piper nigrum L. which known as the main source of the most popular spices and is used worldwide. According to the United Nations Statistics Food and Agriculture Organisation (FAOSTAT), Malaysia was the seventhlargest pepper producer in the world in 2017. Approximately, $98 \%$ of pepper production comes from Sarawak, the country's largest producer. In the meantime, the other $2 \%$ is produced in Johor and other states in Malaysia. The pepper berries of Kuching, Semengok Emas and Semengok Aman are some of the recommended varieties based on the Malaysian Pepper Board (MPB). The differences among these varieties were growth level, amount of yielding and thickness of the pericarp. According to Malaysian Pepper Board (MPB) and Megat et al. (2020), the most preferred variety for the production of white pepper is Kuching meanwhile, Semengok Emas and Semengok Aman have preferred variety for the black pepper production.

Peppers are rich in vitamin A, C and $\mathrm{K}$ which help to reduce the disease and support immune function.
According to Vasavirama and Upender (2014), people take white pepper to reduce malaria, stomach upset, cancer and cholera. It may help control germs or microbes that can cause the flow of digestive juices to increase in the stomach. For black pepper, it consists of high amounts of glutathione peroxidase and glucose-6phosphate dehydrogenase (Karthikeyan and Rani, 2003). Black pepper might help to treat the disease which it may be as antibiotics, antimutagenic, antibacterial, antidiarrhoeal, anti-inflammatory and anti-tumour effects (Srinivasan, 2007; El-Houseiny et al., 2019).

Pepper quality is an important factor in pepper production. To achieve the appropriate uniformity of the raw materials for further processing, processing techniques are important including sorting and grading. The manual sorting and grading methods are timeconsuming and vulnerable to inaccuracy due to human assumptions (Fauzi et al., 2015). The physicochemical properties such as dimensions, weight, volume, density, moisture content and colour can be as the measurement that helps in the classification of pepper berries based on the different of maturity levels. 
There are some regression relationships, such as linear, quadratic, s-curve and power. The statistical significance in the regression relationship shows that in the dependent variable modifications in the dependent variables correlate with shifts. Therefore, the high coefficient of determination $\left(R^{2}\right)$ value means that the model explains a decent percentage of the variability in the dependent variable. The determination of correlations between mass with its physical properties as this technique is more specific for automatic classification of most fruits. In other researches, there are many valuable studies that concerned about mass modelling of fruits based on their properties including kinnow mandarin (Mahawar et al., 2019), chebula fruit (Pathak, Pradhan and Mishra 2019), date (Khodabakhshian and Emadi 2016), pomelo (Nur Salihah et al., 2015), persimmon (Feizollah and Satar 2014), fava bean (Lorestani and Ghari 2012) and onion (Ghabel et al., 2010). However, there is no previous study has investigated in detail on the mass prediction of pepper berries due to a little published data on the mass prediction of berries by using the model equation when compared to fruits. Few published studies that related to berries have focussed on raisin berries (Karimi et al. 2011) and sea buckthorn berries (Jaiswal et al., 2017). The aims of this study were 1) to determine some physical properties of pepper berries and 2) to determine the most applicable model for predicting pepper berries mass by their physical properties. The results of the study may help to provide useful information as to form an essential database for other researchers and also can be applied for improvement in handling and packaging system in future.

\section{Materials and methods}

\subsection{Sample preparation}

Fresh mature pepper berries were obtained from a variety of Kuching. The pepper berries were transferred under room temperature to the laboratory directly from a farm located in Johor, Malaysia. Colour is an essential visual parameter used for sample selection to differentiate pepper based on maturity levels. Therefore, the dark green or yellowish-green berries were selected which labelled as mature pepper berries. They were washed under running tap water to clean from dirt. One hundred samples of mature pepper berries were selected and used to measure physical properties, as shown in Table 1. All the experiments were carried out in the laboratory at room temperature.

\subsection{Determination of physical properties}

Pepper berry mass $(M)$ was determined with $0.01 \mathrm{~g}$ sensitivity of a digital balance (ER-120A, AND, Japan).
Major axis $(L)$, medium axis $(T)$ and minor axis $(W)$ were named for three linear dimensions were measured by using a digital vernier calliper (Series 500, Mitutoyo, Japan) with $0.01 \mathrm{~mm}$ sensitivity as to determine the average size of the samples. The dimensions of the sample were measured as the major axis $(L)$, medium axis $(T)$ and minor axis $(W)$ as shown in Figure 1.

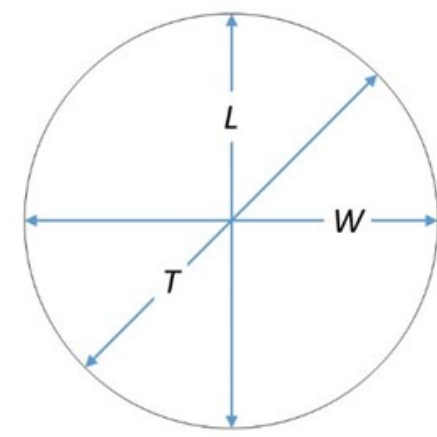

Figure 1. Dimensions of pepper berry

The aspect ratio $(A R)$, geometric mean diameter $\left(D_{g}\right)$ were calculated by using the following formulas (Feizollah and Satar, 2014), respectively:

$$
\begin{aligned}
& A R=\frac{L}{W} \\
& D_{g}=(L W T)^{\frac{1}{a}}
\end{aligned}
$$

The method of water displacement (Rosnah and Chan, 2014; Ravindran and Kallupurackal, 2001) was used to determine the actual volume $(V)$. The uniform presumed shape of the fruit can be as an aspect to determine the accuracy of fruit volume (Feizollah and Satar 2014). The shape of the pepper berry was assumed to be a standard spherical. Therefore, the spherical volume $\left(V_{s p}\right)$ was determined using equation 3 (Khoshnam et al., 2007).

$V_{s p}=\frac{4 \pi}{3}(r)^{3}$

Projected areas of pepper berries $\left(P A_{L}, P A_{T}\right.$ and $\left.P A_{W}\right)$ in three perpendicular directions to dimensions (major axis, medium axis and minor axis) and the criteria projected area $(C P A)$ were calculated by using equation (4), 5), (6) and (7), respectively. These equations were suggested by Mohsenin (1986) and Nur Salihah et al. (2015) and defined as follows:

$$
\begin{aligned}
& P A_{L}=\frac{\pi L W}{4} \\
& P A_{T}=\frac{\pi T W}{4} \\
& P A_{W}=\frac{\pi W W}{4} \\
& C P A=\frac{P A_{L}+P A_{T}+P A_{W}}{3}
\end{aligned}
$$

\subsection{Regression analysis and mass modelling}

The model considerations to predict the mass of pepper berries based on the measurement of physical 
properties as follows:

Single variable regression of pepper berry mass based on dimensional characteristics of pepper berry: major axis $(L)$, medium axis $(T)$, minor axis $(W)$ and geometric mean diameter $\left(D_{g}\right)$.

Single regression of pepper berries volumes: actual volume $(V)$, the volume of the fruit assumed as a $\operatorname{spheroid}\left(V_{s p}\right)$.

Single variable regression of pepper berries projected areas: $P A_{L}, P A_{T}, P A_{W}$ and $C P A$

Four models including Linear, Quadratic, S-curve and Power were used and fitted with the results obtained from experiments. These models are presented in the following Equation (8), (9), (10) and (11) respectively (Lorestani and Ghari, 2012; Feizollah and Satar, 2014):

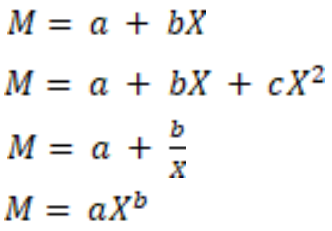

Where $\mathrm{M}=$ mass $(\mathrm{g}) ; \mathrm{X}=$ the value of an independent parameter (physical properties) which to find the relationship of it with mass; $a, b$ and $c=$ curve fitting parameters which are different in each equation.

\subsection{Statistical analysis}

Data analysis and mass modelling prediction was performed by using statistical software such as SigmaPlot (Version 12.0) with significant at $1 \%$ probability level. Coefficient of determination $\left(R^{2}\right)$ and standard error of estimate (SEE) was selected as the criterion to evaluate the applicability of the regression models. The Applicable models were selected by having models with higher $R^{2}$ and lower $S E E$ values (Mahawar et al., 2019).

\section{Results and discussion}

\subsection{Physical properties of pepper berries}

The results of physical properties of pepper berries are summarized in Table 1. The physical properties were found with $75.92 \%$ wet basis of moisture content. The mean values of the major axis, medium axis and minor axis for pepper berries are $5.55 \pm 0.66 \mathrm{~mm}, 5.60 \pm 0.58 \mathrm{~mm}$ and $5.67 \pm 0.51 \mathrm{~mm}$, respectively. In the result of dimensional characteristics, the minor axis has the highest value of mean when compared to the major and medium axis of pepper berries.

The mean values of the geometric mean diameter and aspect ratio of pepper berries are $5.61 \mathrm{~mm}$ and 0.98 with a standard deviation of 0.46 and 0.13 . The weight of pepper berry has an average value which is $0.15 \pm 0.04 \mathrm{~g}$. The other physical properties of pepper berry such as actual volume $\left(120 \pm 21.60 \mathrm{~mm}^{3}\right)$, and spherical volume $\left(94.10 \pm 24.41 \mathrm{~mm}^{3}\right)$. The results of the average projected area which are perpendicular to the major axis, medium axis and minor axis such as $24.78 \pm 4.27 \mathrm{~mm}^{2}, 25.10 \pm 4.51$ $\mathrm{mm}^{2}, 25.45 \pm 4.56 \mathrm{~mm}^{2}$. The criteria projected area of pepper berry was $25.11 \pm 4.56 \mathrm{~mm}^{2}$. Projected areas values are fundamental information in the design and development of machine vision-based grading systems (Mahawar et al., 2019). Also, the measured distinction in the physical properties may due to the inherent variation in fruit dimensional characteristics.

Table 1. Some physical properties of pepper berries.

\begin{tabular}{cccc}
\hline Parameter & Mean & $\begin{array}{c}\text { Maximum } \\
\text { value }\end{array}$ & $\begin{array}{c}\text { Minimum } \\
\text { value }\end{array}$ \\
\hline $\mathrm{L}(\mathrm{mm})$ & $5.55 \pm 0.66$ & 7.4 & 4.36 \\
$\mathrm{~T}(\mathrm{~mm})$ & $5.60 \pm 0.33$ & 7.1 & 4.31 \\
$\mathrm{~W}(\mathrm{~mm})$ & $5.67 \pm 0.51$ & 7.01 & 4.36 \\
$\mathrm{AR}$ & $0.98 \pm 0.13$ & 1.18 & 0.79 \\
$\mathrm{D}_{\mathrm{g}}(\mathrm{mm})$ & $5.61 \pm 0.46$ & 7.17 & 4.67 \\
$\mathrm{Weight}(\mathrm{g})$ & $0.15 \pm 0.04$ & 0.23 & 0.11 \\
$\mathrm{~V}\left(\mathrm{~mm}^{3}\right)$ & $120 \pm 21.60$ & 140 & 90 \\
$\mathrm{~V}_{\mathrm{sp}}\left(\mathrm{mm}^{3}\right)$ & $94.10 \pm 24.41$ & 193 & 54.13 \\
$\mathrm{PA}_{\mathrm{L}}\left(\mathrm{mm}^{2}\right)$ & $24.78 \pm 4.27$ & 40.74 & 17.7 \\
$\mathrm{PA}_{\mathrm{T}}\left(\mathrm{mm}^{2}\right)$ & $25.10 \pm 4.51$ & 39.09 & 14.96 \\
$\mathrm{PA}_{\mathrm{W}}\left(\mathrm{mm}^{2}\right)$ & $25.45 \pm 4.56$ & 38.59 & 14.93 \\
$\mathrm{CPA}_{\left(\mathrm{mm}^{2}\right)}$ & $25.11 \pm 4.13$ & 39.48 & 16.29 \\
\hline
\end{tabular}

Data are expressed as mean $\pm \mathrm{SD} ; L$, major axis; $T$, medium axis; $W$, minor axis; $A R$, aspect ratio; $D_{g}$, geometric diameter; $V$, actual volume; $V_{s p}$, spherical volume; $P A_{L}$, projected area perpendicular to major axis; $P A_{T}$, projected area perpendicular to medium axis; $P A_{W}$, projected area perpendicular to minor axis; $C P A$, criteria projected area.

\subsection{Mass modelling}

The average dimensions, volume, weight and projected areas of pepper berries obtained are used in mass modelling. The best models obtained and their coefficient of determination $\left(R^{2}\right)$ and $(S E E)$ for mass prediction of pepper berries are shown in Table 2. The regression mass is evaluated by using the coefficient of determination $\left(R^{2}\right)$ value.

\subsubsection{Modelling based on dimensions}

The major axis $(L)$, medium axis $(T)$, minor axis $(W)$ and geometric mean diameter $\left(D_{g}\right)$ showed that Quadratic model is the best-fitted model used to calculate and evaluate the mass of pepper berries, respectively. The fitted models based on dimensions such as $L, T, W$ and $D g$ with the values of $R^{2}$ and $S E E$ are 
Table 2. The best mass models for predicting the mass of mature pepper berries based on selected independent parameters

\begin{tabular}{cccccccc}
\hline \multirow{2}{*}{$\begin{array}{c}\text { Dependent } \\
\text { parameter }\end{array}$} & Independent & The best- & \multicolumn{3}{c}{ Regression constant } & \multicolumn{2}{c}{ Statistical parameters } \\
\cline { 4 - 8 } & parameter & fitted model & $\mathrm{a}$ & $\mathrm{b}$ & $\mathrm{c}$ & $R^{2}$ & SEE \\
\hline $\mathrm{M}(\mathrm{g})$ & $\mathrm{L}(\mathrm{mm})$ & Quadratic & 0.351 & -0.107 & 0.012 & 0.980 & 0.007 \\
$\mathrm{M}(\mathrm{g})$ & $\mathrm{T}(\mathrm{mm})$ & Quadratic & 0.419 & -0.133 & 0.015 & 0.883 & 0.017 \\
$\mathrm{M}(\mathrm{g})$ & $\mathrm{W}(\mathrm{mm})$ & Quadratic & 0.557 & -0.186 & 0.020 & 0.926 & 0.014 \\
$\mathrm{M}(\mathrm{g})$ & $\mathrm{Dg}(\mathrm{mm})$ & Quadratic & 0.479 & -0.152 & 0.016 & 0.886 & 0.017 \\
$\mathrm{M}(\mathrm{g})$ & $\mathrm{V}\left(\mathrm{mm}^{3}\right)$ & Quadratic & 0.828 & -0.015 & $7.376 \times 10^{-5}$ & 0.995 & 0.006 \\
$\mathrm{M}(\mathrm{g})$ & $\mathrm{V}_{\mathrm{sp}}\left(\mathrm{mm}^{3}\right)$ & Quadratic & 0.076 & 0.001 & $9.340 \times 10^{-7}$ & 0.993 & 0.004 \\
$\mathrm{M}(\mathrm{g})$ & $\mathrm{PA}_{\mathrm{L}}\left(\mathrm{mm}^{2}\right)$ & Quadratic & 0.158 & -0.005 & $1 \times 10^{-4}$ & 0.835 & 0.020 \\
$\mathrm{M}(\mathrm{g})$ & $\mathrm{PA}_{\mathrm{T}}\left(\mathrm{mm}^{2}\right)$ & Quadratic & 0.199 & -0.009 & $2 \times 10^{-4}$ & 0.930 & 0.013 \\
$\mathrm{M}(\mathrm{g})$ & $\mathrm{PA}_{\mathrm{W}}\left(\mathrm{mm}^{2}\right)$ & Quadratic & 0.207 & -0.010 & $3 \times 10^{-4}$ & 0.942 & 0.012 \\
$\mathrm{M}(\mathrm{g})$ & $\mathrm{CPA}$ & Quadratic & 0.221 & -0.011 & $3 \times 10^{-4}$ & 0.966 & 0.009 \\
\hline
\end{tabular}

Data are expressed as $L$, major axis; $T$, medium axis; $W$, minor axis; $A R$, aspect ratio; $D_{g}$, geometric diameter; $V$, actual volume; $V_{s p}$, spherical volume; $P A_{L}$, projected area perpendicular to major axis; $P A_{T}$, projected area perpendicular to medium axis; $P A_{W}$, projected area perpendicular to minor axis; $C P A$, criteria projected area; $R^{2}$, coefficient of determination; $S E E$, standard error of estimate; $a, b, c$, constant of curve fitting.

shown in Table 2. $L$ had the highest $R^{2}(0.980)$ and lowest SEE (0.007) value when compared to others as given in Quadratic form (Equation 12)

$M=0.35-0.107 X+0.012 X^{2}$

There is a similar model for onion and Malaysian varieties pomelo fruit in another study that was suggested and reported by Ghabel et al. (2010) and Nur Salihah et al. (2015), which the best model for determination of mass based on $L$ was a Quadratic model as follows Equation 13 and 14:

$M=36.137-1.64 X+0.35 X^{2}, R^{2}=0.96$

$M=28500.33-417.191 X+1.587 X^{2}, R^{2}=0.993$

For the entire dimensions, the S-curve model reported having lower $R^{2}$ values as compared with other fitted models. The lower $R^{2}$ values also could be due to there was no uniform mass of pepper berries corresponding to its size. Thus, sizing pepper berries based on length is recommended.

\subsubsection{Modelling based on volume}

In Table 2, the results of mass prediction of the pepper berries based on volumes $\left(V, V_{s p}\right)$, the Quadratic model showed the best model based on the highest value of $R^{2}$ compared to the other models. The highest value of $R^{2}$ and $S E E$ of actual volume, $V$ (Equation 15) are 0.995 and 0.006 meanwhile volume assumed shaped as spherical $\left(V_{s p}\right)$ given the highest value of $R^{2}$ and $S E E$ which are 0.993 and 0.004 as shown in Equation 16. The best models of pepper berries formed as shown in the following equations:

$M=0.828-0.015 X+7.376 \times 10^{-5} X^{2}$

$M=0.076-0.001 X+9.340 \times 10^{-7} X^{2}$

Therefore, a quadratic form had been shown as the suggested mass model-based volume as similar to the prediction of the mass of Fava bean with $R^{2}=0657$ (Lorestani and Ghari, 2012).

\subsubsection{Modelling based on projected areas}

Among the models based on the projected area $\left(P A_{L}\right.$, $P A_{T}, P A_{W}$ and $C P A$ ), Quadratic model comprising $C P A$ (Equation 17) was the best fitted having higher $R^{2}$ of 0.966 and $S E E$ of 0.009 . However, Quadratic model of the projected area based on the minor axis $\left(P A_{W}\right)$ and criteria projected area $(C P A)$ shown in Table 2 was preferred as the best model to calculate the mass of pepper berries. Due to the low $R^{2}$ value, models based on $P A_{L}$ and $P A_{T}$ were found not appropriate for the pepper berries.

$M=0.221-0.011 X+3 \times 10^{-4} X^{2}$

Therefore, all three projected areas are necessary to be specified and apply in grading the pepper berries by using this model.

\section{Conclusion}

In this study, all properties were found to be statistically significant at the $1 \%$ probability level. The pepper berries mass based on actual volume (Quadratic model) was recommended equation as nonlinear form: $M=$ $0.828-0.015 X+7.736 \times 10^{-5} X^{2}$, which has the highest $R^{2}, 0.995$ and lower $S E E, 0.006$. This shows a very good relationship between mass and the actual volume of pepper berries. The model predicts the mass of pepper berries considered as spherical was found to be the most applicable (Quadratic model is recommended). These results of the study may help to provide useful information as to form an essential database for other researchers and also can be applied for improvement in handling and packaging system in future. 


\section{Conflict of interest}

The authors declare no conflict of interest.

\section{Acknowledgments}

The authors express their gratitude to the Universiti Putra Malaysia for providing financial and technical support to conduct this research work.

\section{References}

El-Houseiny, W., Khalil, A.A., Abd-Elhakim, Y.M. and Badr, H.A. (2019). The potential role of turmeric and black pepper powder diet supplements in reversing cadmium-induced growth retardation, ATP depletion, hepatorenal damage, and testicular toxicity in Clarias gariepinus. Aquaculture, 510, 109-121.

j.aquaculture.2019.05.045

FAOSTAT. Retreived from FAO website: http:// www.fao.org/faostat/en/\#data/QC/visualize/.

Fauzi, A.H., Iskandar, D.N.F.A. and Suhaimi, M.A.A. (2015). Automated Machine for Sorting Sarawak Pepper Berries presented at the 9th International Conference on IT in Asia (CITA). Sarawak, Malaysia. https://doi.org/10.1109/ CITA.2015.7349840

Feizollah, S. and Satar, R. (2014). Mass modelling of persimmon fruit with some physical characteristics. Agricultural Engineering International: CIGR Journal, 16, 289-293.

Ghabel, R., Rajabipour, A., Ghasemi-Varnamkhasti, M. and Oveisi, M. (2010). Modelling the mass of Iranian export onion (Allium cepa $\mathrm{L}$.) varieties using some physical characteristics. Research in Agricultural Engineering, 56(1), 33-40. https:// doi.org/10.17221/23/2009-RAE

Jaiswal, S.G., Dole, B.R., Satpathy, S.K. and Naik, S.N. (2017). Physical attributes and modelling of transhimalayan seabuckthorn berries. Current Research in Nutrition and Food Science, 5(3), 391-397. https://doi.org/10.12944/CRNFSJ.5.3.25

Karimi, N., Arabhosseini, A., Kianmehr, M.H. and Khazaei, J. (2011). Modelling of raisin berries by some physical and statistical characteristics. International Agrophysics, 25(2), 141-147.

Karthikeyan, J. and Rani, P. (2003). Enzymatic and nonenzymatic antioxidants in selected Piper species. Indian Journal of Experimental Biology, 41(2), 135140.

Khodabakhshian, R. and Emadi, B. (2016). Mass model of date fruit (cv. Mazafati) based on its physiological properties. International Food Research Journal, 23 (5), 2057-2062.
Khoshnam, F., Tabatabaeefar, A., Varnamkhasti, M.G. and Borghei, A. (2007). Mass modelling of pomegranate (Punica granatum L.) fruit with some physical characteristics. Scientia Horticulturae, 114 (1), 21-26.

https://doi.org/10.1016/ j.scienta.2007.05.008

Lorestani, A.N. and Ghari, M. (2012). Mass modelling of Fava bean (vicia faba L.) with some physical characteristics. Scientia Horticulturae, 133(1), 6-9. https://doi.org/10.1016/j.scienta.2011.10.007

Mahawar, M.K., Bibwe, B., Jalgaonkar, K. and Ghodki, B.M. (2019). Mass modelling of kinnow mandarin based on some physical attributes. Journal of Food Process Engineering, 42(5), 1-11. https:// doi.org/10.1111/jfpe.13079

Malaysian Pepper Board (MPB). Retrieved from MPB website: https://www.mpb.gov.my/mpb2/index.php/ my/.

Megat, A.A.P.N., Shamsudin, R., Che Man, H. and Ya'acob, M.E. (2020). Effect of soaking process on physical properties of mature pepper berries (Piper nigrum L.). Food Research, 4(S1), 116-123. https:// doi.org/10.26656/fr.2017.4(S1).S04

Mohsenin, N.N. (Ed.) (1986). Physical properties of plant and animal materials. Structure, physical characteristics and mechanical properties, p. 31-987. New York: Gordon and Breach Science Publishers.

Nur Salihah, B., Rosnah, S. and Norashikin, A.A. (2015). Mass modelling of Malaysian varieties pomelo fruit (Citrus Grandis L. Osbeck) with some physical characteristics. International Food Research Journal, 22(2), 488-493.

Pathak, S.S., Pradhan, R.C. and Mishra, S. (2019). Physical characterization and mass modelling of dried Terminalia chebula fruit. Journal of Food Process Engineering, 42(3), 1-10. https:// doi.org/10.1111/jfpe.12992

Ravindran, P.N. and Kallupurackal, J.A. (2001). Black Pepper. Handbook of Herbs and Spices. https:// doi.org/10.1201/9781439823002.ch7

Rosnah, S. and Chan, S. (2014). Enzymatic rettings of green pepper berries for white pepper production. International Food Research Journal, 21(1), 237245.

Srinivasan, K. (2007). Black pepper and its pungent principle-piperine: a review of diverse physiological effects. Critical Reviews in Food Scinece and Nutrition, 47(8), 735-748. https:// doi.org/10.1080/10408390601062054

Vasavirama, K. and Upender, M. (2014). Piperine: A Valuable Alkaloid from Piper Spices. International Journal of Pharmacy and Pharmaceutical Science, 6, 34-38. 